\title{
Economics
}

\section{An Adjusted Forward Curve for Spot Rate Forecasting}

\section{Camilo Sarmiento}

The Office of Risk Management, Inter-American Development Bank, Washington DC, USA

\section{Email address:}

csarmientog@verizon.net

\section{To cite this article:}

Camilo Sarmiento. An Adjusted Forward Curve for Spot Rate Forecasting. Economics. Vol. 9, No. 1, 2020, pp. 1-7. doi: $10.11648 /$ j.eco.20200901.11

Received: January 7, 2020; Accepted: January 31, 2020; Published: February 11, 2020

\begin{abstract}
In this paper, we provide adjustments for liquidity and credit risk to the forward Libor rate in order to improve accuracy of the forward rate in forecasting the 3-month Libor rate. In particular, we introduce the adjusted forward curve (AFC) that models the update in the forward curve from one period to the next. A direct modeling of the dynamic process of the forward curve facilitates the specification of adjustment factors to the forward curve, and it underscores the role of mean reversion (stationarity) in the nexus between the forward rate and the future spot rate. The AFC factors that underpin the forward curve bias are statistically relevant with p-values that are less than .00001 . The upward bias in the forward curve (i.e., when the forward curve exceeds the expected future spot rate) positively correlates with the steepness of the yield curve in the AFC model. A downward bias positively correlates with the credit spread and industrial capacity utilization. Furthermore, the effect of the instantaneous forward curve on the future spot rate tempers off with time. The predictive power of the AFC model, however, hinges on the forecastability of the underlying factors. The testing indicates that all the AFC model factors have a mean reversion component. Overall, our model effectively anticipates movements in the forward curve that tend to yield a better forecast of the future spot rate.
\end{abstract}

Keywords: Adjusted Forward Curve, Forecasting Spot Rate, Yield Curve Steepness, Credit Risk, Mean Reversion

\section{Introduction}

The market of interest rates swaps is one of the largest and most liquid in the world. An interest rate swap is a forward contract in which one stream of future interest payments is exchanged for another based on a specified principal amount. Interest rate swaps usually involve the exchange of a fixed interest rate for a floating rate, or vice versa. Swaps are the most commonly used instrument to hedge for interest rate risk. Swaps also provide speculators with instruments to bet on the direction of interest rate movements.

By definition, the interest rate received under the fixed leg of the swap equals the composite interest of the forward curve:

$$
R(t, T)=\left\{\exp \left[-\int_{t}^{T}(f(t, s)) d s\right]\right\}
$$

where $R(t, T)$ is yield of the fixed leg with a tenor of $T-t$; and $f(t, s)$ is the instantaneous forward rate. In the absence of liquidity or credit risk,

$$
E\left(r_{t+h}\right)=f_{t, h}
$$

where $r_{t+h}$ is the instantaneous spot rate at time $\mathrm{t}+\mathrm{h}$, and $f_{t, h}$ is the forward rate at time $t$ with maturity $h$.

Samuelson's [16] original formulation of efficient markets presumes that the forward is the best forecast of the spot rate. Samuelson interprets the future price as concrete observations of the spot price anticipations, and states that examinations of past changes in the forward curve does not improve forecastability. The unbiased expectations hypothesis (see Gibson et al., [10]) states that the forward rate is equal to the future expected spot rate.

However, a rational market does not necessarily imply that the forward price equals the expected future spot rate. In particular, a forward rate is equivalent to a fixed rate bond. This implies that the term structure of the forward price introduces a liquidity premium. Ceteris paribus, this premium implies that the forward rate is larger than the expected future rate. For example, a steeper Treasury curve would imply a larger liquidity premium that results in a lower expected spot rate relative to the forward rate. 
The Libor rate further embeds some credit risk as it captures the interest rate that high-credit quality banks charge one another for short-term financing. This credit risk implies that the forward rate is larger in times of larger credit risk. Longstaff and Schwartz [12] find that credit spreads are negatively related to interest rates. It is expected that the forward rate, however, encompasses less credit risk than the Libor spot rate as the risk of the swap is more widely dispersed

In this paper, we provide adjustments for liquidity and credit risk to the forward Libor rate in order to improve accuracy of the forward rate in forecasting the 3-month Libor rate. ${ }^{1}$ In particular, we introduce the adjusted forward curve (AFC) that models the update in the forward curve from one period to the next. Our model effectively anticipates movements in the forward curve that tend to yield a better forecast of the future spot rate.

\section{An Adjusted Forward Curve}

Fama [8] tests the predictability of the spot price based on information provided by the futures market as follows:

$$
r_{t+h}-r_{t}=\alpha_{h}+\beta_{h}\left(f_{t, h}-r_{t}\right)+\epsilon_{t, h}
$$

where the Libor rate at time $\mathrm{t}$ is represented by $r_{t}$; the forward rate at time $\mathrm{t}$ for time horizon $t+h$ is represented by $f_{t, h}$; and $\epsilon_{t, h}$ is the forecast error.

Cochrane and Piazzesi [5] find that lags of forward rates (in addition to contemporaneous forward rates) contain information about the spot price in (1). Rather than modeling the changes in the spot rate for different time horizons, $h$, as in equation 1, we introduce the adjusted forward curve (AFC) that models the update in the forward curve from one period to the next. That is,

$$
f_{t+1, h-1}-f_{t, h}=\rho f_{t, h}+u_{h, t}+e_{t, h} .
$$

where the term $u_{h, t}$ captures systematic factors that explain forward curve movements from one period to the next, and $e_{t, h}$ is a zero mean stochastic process.

The structure in (2) provides a convenient structure to model factors that contribute to anticipate changes in the forward curve for spot rate forecasting, as it models updates in the forward curve from one period to the next.

The connection between (1) and (2) stems from solving equation 2 recursively, which yields an alternative model representation of the AFC that maps the forward curve to the expected future spot rate. That is,

$$
E\left(r_{t+h}\right)=(\rho+1)^{h} f_{t, h}+\sum_{s=0}^{h-1}(\rho+1)^{s} u_{h-s, t+s}
$$

where $r_{t+h}=f_{t+h, 0}$.

In the AFC model, it is straightforward that the forward rate equals the expected spot rate only if $\rho=0$ and $u_{h, t}=0$. Equation 3, furthermore, indicates that if $\rho<0$, then the

1 Limitations of the forward curve for spot rate forecasting have been well established by Shiller et al. [17]. Fama and Bliss [9], Campbell and Shiller [3], Piazzesi and Swanson [15] and Malkiel [14]. instantaneous change in the forward curve is not fully transmitted to the future spot rate, and the effect tampers off with the forecast horizon. One direct implication of stationarity is that updates to the forward curve become much less relevant to predict the spot rate in longer time horizons. Furthermore, under stationarity, the marginal effect of the forward curve on the future spot price collapses into a single parameter than tapers off similarly to a lagged dependent variable. This structure releases degrees of freedom that can be used to examine other factors that explain the future spot rate in addition to the forward curve.

Overall, different from the structure in (1), a direct modeling of the dynamic process of the forward curve in (2) facilitates the specification of adjustment factors to the forward curve, and it underscores the role of mean reversion (stationarity) in the nexus between the forward rate and the future spot rate.

\section{AFC Model Estimation}

\subsection{Data Processing}

To estimate the AFC model in (2), we collected a historical series of the forward curve from Bloomberg. The data set consists of the 3-month Libor forward for a projection of 10years. The data spans 116 forward curves that span from 1990 to the present in a quarterly basis.

The raw data in Figure 1 consists of a matrix format with dimension $40 \times 116$. Each raw consists of the forward curve and each column represents a calendar time. Each element of the matrix is defined as $f_{t, h}$ where $(\mathrm{t}, \mathrm{h})$ is located at column $\mathrm{t}$ and row h.

The processing of the data to capture the dynamic process in Equation 2 (i.e., the dependent variable of the AFC model) is illustrated in Figure 2. All data processing steps are conducted in Matlab.

\subsection{AFC Model Parameter Estimation}

This section uses the AFC model structure to introduce both a liquidity premium and a credit risk adjustment to the forward curve in the forecasting of the spot rate. Table 1 shows both the liquidity and credit risk factors to be added to the model and expected impact.

The premise that the term and the credit spread are the main drivers of the bias associated with the use of the forward curve on spot rate forecasting is consistent with previous work that shows that bond spreads are main leading indicators of economic activity (Stock and Watson [18]; Estrella and Hardouvelis [7]). Among others, Bernanke [2] suggests that the term spread is the best predictor of monetary stance. Consistent with Hicks' liquidity preference model, a larger preference for liquidity is captured by the steepness of the yield curve. Longstaff and Schwartz [12] find that credit spreads are negatively related to interest rates. Lastly, in the context of Gordon [11], capacity utilization is the main driver of the trade-off of inflation and output and, therefore, a proxy for liquidity. More recently, Ludvigson and $\mathrm{Ng}$ [13] underscore the industrial production effect on bond risk premia. 


\begin{tabular}{|c|c|c|c|c|c|c|c|c|c|c|}
\hline Interval 3 & $3 \mathrm{MO}$ & Tenor & $3 \mathrm{MO}$ & Up to & $10 \mathrm{YR}$ & & & & & \\
\hline & & & & & & & & & & \multirow{3}{*}{$\rightarrow$} \\
\hline & & & \multirow{2}{*}{\multicolumn{2}{|c|}{ Forward Curve As of }} & & & & & & \\
\hline & & & & & & & & & & \\
\hline & & Projected Quarter & 1/15/1990 & 4/15/1990 & $7 / 15 / 1990$ & $10 / 15 / 1990$ & 1/15/1991 & 4/15/1991 & 7/15/1991 & $10 / 15 / 1991$ \\
\hline & & 1 & 8.312 & 8.500 & 8.187 & 8.250 & 7.560 & 6.060 & 6.062 & 5.375 \\
\hline & & 2 & 8.053 & 8.562 & 8.024 & 7.911 & 7.309 & 6.445 & 6.516 & 5.491 \\
\hline & & 3 & 8.130 & 8.645 & 8.025 & 7.854 & 7.284 & 6.686 & 6.904 & 5.434 \\
\hline & & 4 & 8.278 & 8.832 & 8.116 & 7.960 & 7.437 & 7.098 & 7.055 & 5.656 \\
\hline & & 5 & 8.483 & 8.975 & 8.304 & 8.193 & 7.675 & 7.376 & 7.444 & 6.032 \\
\hline \multirow{4}{*}{\multicolumn{2}{|c|}{$\begin{array}{l}\text { Projected date } \\
\text { interval in } \\
\text { Quarters }\end{array}$}} & 6 & 8.547 & 9.076 & 8.483 & 8.506 & 7.812 & 7.710 & 7.850 & 6.456 \\
\hline & & 7 & 8.494 & 9.091 & 8.611 & 8.610 & 8.138 & 7.916 & 8.102 & 6.739 \\
\hline & & 8 & 8.198 & 9.076 & 8.610 & 8.659 & 8.524 & 7.979 & 8.183 & 7.181 \\
\hline & & 9 & 8.586 & 9.252 & 8.820 & 8.938 & 8.321 & 8.253 & 8.397 & 7.257 \\
\hline & & 10 & 8.619 & 9.309 & 8.899 & 9.045 & 8.419 & 8.443 & 8.591 & 7.475 \\
\hline & & 11 & 8.651 & 9.356 & 8.967 & 9.143 & 8.508 & 8.616 & 8.767 & 7.679 \\
\hline & & 12 & 8.673 & 9.393 & 9.029 & 9.232 & 8.587 & 8.772 & 8.930 & 7.863 \\
\hline & & 13 & 8.938 & 9.371 & 9.252 & 9.343 & 8.922 & 8.403 & 8.352 & 7.268 \\
\hline & & 14 & 8.978 & 9.391 & 9.314 & 9.411 & 9.013 & 8.480 & 8.408 & 7.343 \\
\hline & & 15 & 9.012 & 9.404 & 9.365 & 9.471 & 9.094 & 8.547 & 8.456 & 7.412 \\
\hline & & 16 & 9.038 & 9.407 & 9.410 & 9.521 & 9.164 & 8.606 & 8.514 & 7.476 \\
\hline \multicolumn{2}{|r|}{ 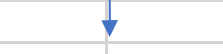 } & 17 & 8.941 & 9.491 & 9.241 & 9.380 & 9.323 & 9.276 & 9.962 & 9.170 \\
\hline & & 18 & 8.948 & 9.493 & 9.256 & 9.400 & 9.381 & 9.365 & 10.091 & 9.341 \\
\hline
\end{tabular}

Figure 1. Raw Data.

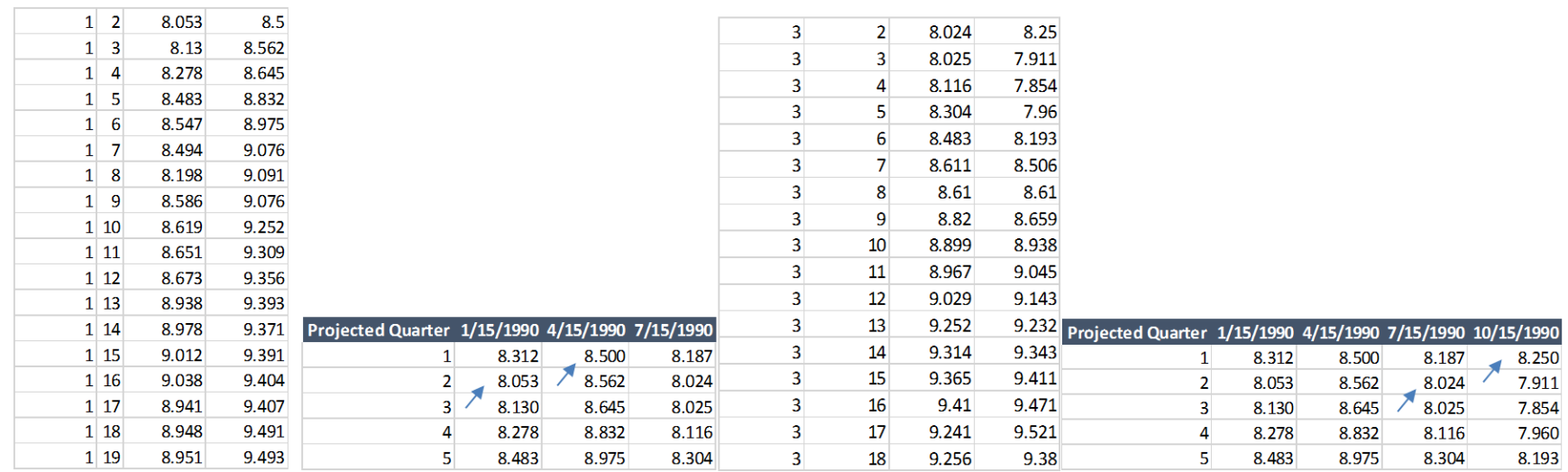

Figure 2. Processed Data.

Table 1. Liquidity and Credit Factors in the AFC Model.

\begin{tabular}{|c|c|c|}
\hline Factor & Variable & Forward Curve Impact \\
\hline Liquidity Premium & $\begin{array}{l}\text { 1. Term spread between the } 10 \mathrm{Y} \text { and } 2 \mathrm{Y} \text { Treasury. } \\
\text { 2. Term spread between the } 2 \mathrm{Y} \text { and } 3 \mathrm{M} \text { Treasury bill. } \\
\text { 3. Industrial capacity. }\end{array}$ & $\begin{array}{l}\text { Adjusts the Forward Curve Downward- Reduces Upward } \\
\text { Bias. }\end{array}$ \\
\hline Credit Risk & Credit Spread. & $\begin{array}{l}\text { Adjusts the Forward Curve Upward- Reduces downward } \\
\text { Bias. }^{2}\end{array}$ \\
\hline
\end{tabular}

Accordingly, we model the adjustment factor of the forward curve for spot rate forecasting as follows:

$$
u_{h, t}=a_{1}+g(h)+a_{2} \cdot C S_{\mathrm{t}-1}+a_{3} \cdot \operatorname{spread}_{\mathrm{t}-1,10 \mathrm{Y}-2 \mathrm{Y}}+a_{4} \cdot \operatorname{spread}_{\mathrm{t}-1,2 \mathrm{Y}-3 \mathrm{M}}+a_{5} \cdot\left(I C_{\mathrm{t}-1}-\overline{I C}\right)
$$

where

spread $_{\mathrm{t}-1,10 \mathrm{Y} \text { to } 2 \mathrm{Y}}=$ the term spread between the $10 \mathrm{Y}$ and $2 \mathrm{Y}$ Treasury bill at time $\mathrm{t}-1$;

spread $_{\mathrm{t}-1,2 \mathrm{Y} \text { to } 3 \mathrm{M}}=$ the term spread between the $2 \mathrm{Y}$ and $3 \mathrm{M}$ Treasury bill at time $\mathrm{t}-1$; and 
$C S_{\mathrm{t}-1}=$ credit spread at time $\mathrm{t}-1 ;{ }^{3}$ and $I C_{\mathrm{t}-1}$ is the industrial capacity at time $\mathrm{t}-1$ with a historical average level of $\overline{I C}$.

Furthermore, after testing different model specifications, we pin down the following structure for $g(h)$ in Equation 4 :

$$
g(h)=b_{1} I_{1}+b_{2} I_{2}, \text { for } I_{1}=1 \text { if } h>10(i . e ., h>10 \text { quarters horizon) }
$$

and

$$
I_{1}=0 \text {, else; and } I_{2}=1 \text { if } h>20 \text { and } I_{2}=0 \text {, else. }
$$

Table 2 shows the coefficient estimates of the AFC model under (4). These estimates reveal the presence of significant biases that relate to the use of the forward curve in spot rate forecasting of the 3-month Libor rate, and this bias changes with liquidity and credit risk factors. ${ }^{4}$

Table 2. Parameter Estimates of Equation 6.

\begin{tabular}{lllll}
\hline Variable Coefficient & Estimate & SE & tStat & p-value \\
\hline AFC Model & & & & \\
$a_{1}$ & -0.272 & 0.048 & -5.619 & 3.756 \\
$b_{1}$ & 0.088 & 0.023 & 4.735 & 0.000175 \\
$b_{2}$ & 0.093 & 0.020 & -8.511 & $2.26 \mathrm{E}-06$ \\
$\rho$ & -0.043 & 0.005 & 12.296 & $2.34 \mathrm{E}-17$ \\
$a_{2}$ & 0.204 & 0.017 & -15.287 & $2.02 \mathrm{E}-51$ \\
$a_{3}$ & -0.328 & 0.021 & -11.036 & $6.03 \mathrm{E}-28$ \\
$a_{4}$ & -0.296 & 0.027 & 8.476 & $3.16 \mathrm{E}-17$ \\
$a_{5}$ & 0.031 & 0.004 & & \\
\hline
\end{tabular}

\begin{tabular}{|c|c|c|c|c|c|c|}
\hline AR (1) Model & Coefficients & Standard Error & t Stat & P-value & Lower $95.0 \%$ & Upper $95.0 \%$ \\
\hline \multicolumn{7}{|l|}{ Credit Spread } \\
\hline Intercept & 0.31 & 0.14 & 2.17 & 0.03 & 0.03 & 0.60 \\
\hline Lagged Dep. Var. & 0.93 & 0.03 & 27.92 & 0.00 & 0.86 & 0.99 \\
\hline \multicolumn{7}{|c|}{ Term Spread 2-year to 3-month Treasury } \\
\hline Intercept & 0.17 & 0.05 & 3.48 & 0.00 & 0.07 & 0.27 \\
\hline Lagged Dep. Var. & 0.72 & 0.06 & 11.20 & 0.00 & 0.59 & 0.85 \\
\hline \multicolumn{7}{|c|}{ Term Spread 10-year to 2-year Treasury } \\
\hline Lagged Dep. Var. & 0.93 & 0.03 & 28.22 & 0.00 & 0.87 & 1.00 \\
\hline \multicolumn{7}{|c|}{ Industrial Capacity Utilization } \\
\hline Intercept & -0.05 & 0.10 & -0.46 & 0.65 & -0.24 & 0.15 \\
\hline Lagged Dep. Var. & 0.96 & 0.02 & 40.26 & 0.00 & 0.91 & 1.01 \\
\hline
\end{tabular}

Table 3. Mean Reversion Testing to AFC Model Factors.

\begin{tabular}{|c|c|c|c|}
\hline Year & $F C . M S E_{t, Y}-A F C . M S E_{t, Y}$ & t-stat & Preferable Model \\
\hline 2014 & 0.05 & 9.50 & $\mathrm{AFC}$ \\
\hline 2008 & 0.47 & 8.44 & $\mathrm{AFC}$ \\
\hline 2007 & 0.19 & 7.35 & $\mathrm{AFC}$ \\
\hline 2002 & 0.19 & 5.72 & $\mathrm{AFC}$ \\
\hline 1993 & 0.18 & 5.54 & $\mathrm{AFC}$ \\
\hline 2013 & 0.04 & 5.15 & $\mathrm{AFC}$ \\
\hline 1998 & 0.05 & 5.12 & $\mathrm{AFC}$ \\
\hline 2016 & 0.03 & 5.08 & $\mathrm{AFC}$ \\
\hline 2001 & 0.13 & 4.72 & $\mathrm{AFC}$ \\
\hline 1991 & 0.11 & 4.48 & $\mathrm{AFC}$ \\
\hline 1999 & 0.03 & 4.28 & $\mathrm{AFC}$ \\
\hline 1992 & 0.24 & 3.80 & $\mathrm{AFC}$ \\
\hline 2000 & 0.02 & 3.78 & $\mathrm{AFC}$ \\
\hline 1995 & 0.09 & 3.56 & $\mathrm{AFC}$ \\
\hline 2012 & 0.03 & 3.34 & $\mathrm{AFC}$ \\
\hline 2011 & 0.06 & 2.80 & $\mathrm{AFC}$ \\
\hline 1997 & 0.04 & 2.57 & $\mathrm{AFC}$ \\
\hline 2010 & 0.00 & -0.20 & Undetermined \\
\hline 2006 & 0.00 & -0.29 & Undetermined \\
\hline
\end{tabular}

Table 4. Backtesting the AFC Model.

3 Moody's Seasoned Baa Corporate Bond Minus Federal Funds Rate.

4 While stepwise regression suggested that other factors may also enter into the model (e.g., Nominal GDP growth, real GDP growth, manufacturing index, the ratio of budget deficit to GDP), the selection is not robust to different cuts of the data. Furthermore, University of Michigan: Inflation Expectations have a very significant effect on the bias, but the factor makes the model unduly dependent to the estimation period, or alternatively stated, makes the model projections much less robust. 


\begin{tabular}{llll}
\hline Year & $\boldsymbol{F C} . \boldsymbol{M S} \boldsymbol{E}_{\boldsymbol{t}, \boldsymbol{Y}}-\boldsymbol{A F C} \boldsymbol{.} \boldsymbol{M} \boldsymbol{S} \boldsymbol{E}_{\boldsymbol{t}, \boldsymbol{Y}}$ & t-stat & Preferable Model \\
\hline 2005 & 0.00 & -0.34 & Undetermined \\
2003 & -0.02 & -1.12 & Undetermined \\
2009 & -0.06 & -2.15 & Forward Curve \\
1996 & -0.02 & -2.48 & Forward Curve \\
2017 & -0.02 & -5.09 & Forward Curve \\
1994 & -0.27 & -11.51 & Forward Curve \\
2015 & -0.10 & -13.94 & Forward Curve \\
\hline
\end{tabular}

The model estimates in Table 2 reveal biases from using the forward rate in projecting the spot rate. The AFC factors that underpin the forward curve bias are statistically relevant with pvalues that are less than .00001 . Consistent with the expectations in Table 1, the upward bias in the forward curve (i.e., when the forward curve exceeds the expected future spot rate) in Table 2 positively correlates with the steepness of the yield curve in the AFC model. Furthermore, a downward bias positively correlates with the credit spread and industrial capacity utilization. Lastly, the effect of the instantaneous forward curve on the future spot rate tempers off with time, $\rho<0$.

The predictive power of the AFC model, however, hinges on the forecastability of the underlying factors. Table 3 shows that all the AFC model factors have a mean reversion component. Therefore, the AFC model should improve long term forecast of the spot rate by adjusting the forward curve with liquidity and credit risk factors that tend to revert to the mean.

Similar to Duffee [6], the results in Table 3 contrast with a lack of mean reversion in the 3-month Libor rate. Specifically, implementation of the Dickey-Fuller Test cannot reject the null hypothesis that the 3-month Libor rate follows a random walk process. This result, however, stems from the post Great Recession period, in which the mean reversion component is no longer statistically significant. The literature in interest rate

$$
F C . M S E_{t, Y}-A F C . M S E_{t, Y}=\sum_{h=2}^{40} \sum_{t=Q 1 . Y}^{Q 4 . Y}\left[\frac{\left(f_{t+1, h-1}-f_{t, h}\right)^{2}}{120}-\frac{\left(f_{t+1, h-1}-f_{t, h}-\rho f_{t, h}-u_{h, t}\right)^{2}}{120}\right]
$$

for $\mathrm{Y}=1990$ to 2018 , where $F C . M S E_{t, Y}$ is the mean square error associated with changes in the forward curve from one quarter to another for year Y; and $A F C . M S E_{t, Y}$ is the mean square error associated with same movements of the AFC.

The availability of large number of observations allows us to examine years in which the difference is statistically significant. The results of the testing are presented in Table 4.

Overall, the backtesting of the AFC model in Table 4 reveals that the AFC model tends to out-perform the forward curve. Specifically, across the 27 years in the sample period, there were 17 instances in which the MSE was statistically lower under the AFC model than under the forward curve; there were 5 instances in which the MSE was statistically lower under the forward curve relative to the AFC; and 5 instances in which the MSE error was not statistically different between the two models.

Therefore, the use of the AFC tends to successfully detect the bias associated with the use of the forward curve in the majority of instances, and the bias depends on liquidity and credit risk factors. For example, projecting updates to the forward curve require modeling changes in the liquidity premium (e.g., the steepness of the Treasury curve). Similarly, projecting updates to the forward price need to capture changes in credit spreads. modeling that was built prior to the Great Recession suggests the presence of mean reversion. Bauer and Rudebusch [1] and $\mathrm{Wu}$ and Xia [19] examine interest rates in the post Great Recession period.

Overall, the use of the AFC curve in medium to long run forecasting of the spot rate benefits from the presence of mean reversion on its underlying factors, and the current level of the forward curve only has a transitory effect on the future (expected) spot rate.

\section{Backtesting}

\subsection{Mean Square Error (MSE) Testing}

Clark and McCracken [4] emphasize the important role of pseudo out-of-sample forecasts in econometric evaluation of forecasting models. To measure the model performance, we backtest the model for each year of the sample. The performance year used in the testing is excluded from the AFC model estimation; so it is an out-of-sample test. We then calculate the MSE for both the forward curve and the AFC, and we determine if the differences between the MSEs are statistically significant. Specifically, the structure of the test is:

\subsection{The Viability of Mean Reversion in AFC Model}

The back-testing indicates that the AFC model tends to successfully detect the sign of the bias in spot rate forecasting and, therefore, in effectively monitoring the accuracy of changes in the forward curve. However, the main value of the adjustment may stem from the property of mean reversion of its underlying factors.

Figures 3 to 5 show that the AFC evaluated in terms of long run value of the factors (i.e., historical averages of each factor) relative to the forward curve in various long-term forecasting horizons. The figures use the forward curve that originated from Jan 1990, Jan 2000, and Jan 2008. The main takeaway from the analysis is that the property of mean reversion for liquidity and credit risk factors increase the viability of the adjustment factors of the forward curve. Of course, implementation of more sophisticated models for forecasting the underlying factors in the AFC model are likely to produce further gains in model performance.

The AFC model (evaluated at the long run value of its underlying factors) also appears to perform reasonably well in medium term forecasts. The figures illustrate the differences between the AFC and the forward curve relative to the actual 
spot rate in a span of 4-years. Figures 6 and 7 use the forward curve that originated in Jan 2014 and Jan 2015, respectively.

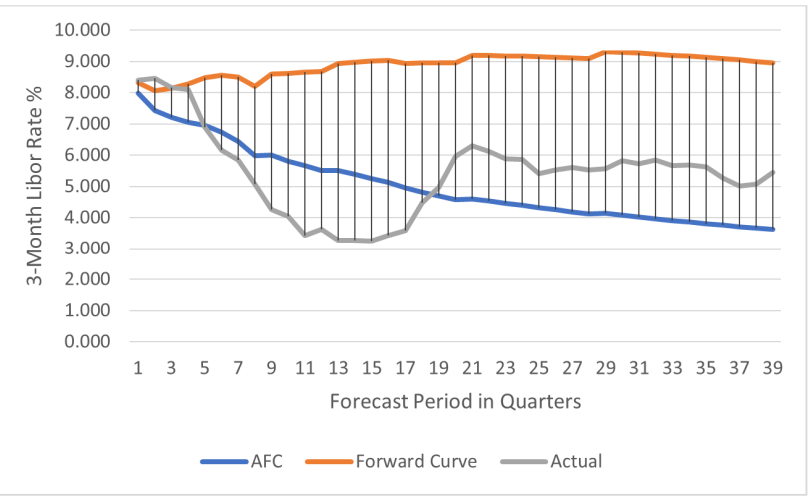

Figure 3. AFC Versus Forward Curve Starting in 1990.

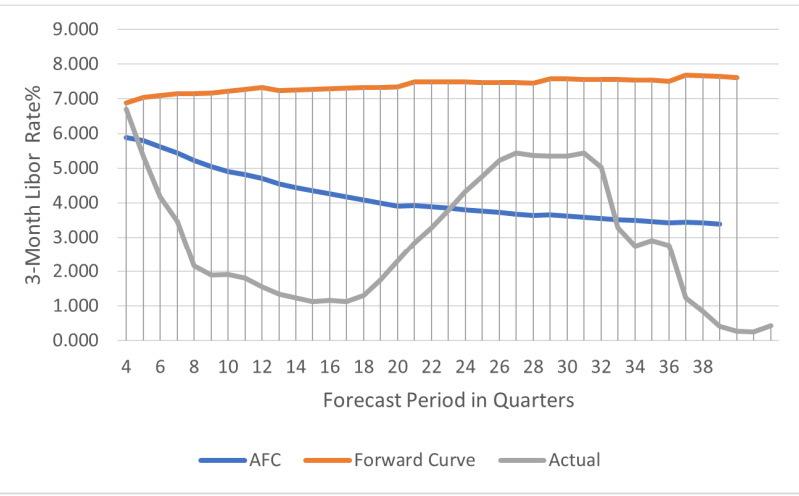

Figure 4. AFC Versus Forward Curve Starting in 2000.

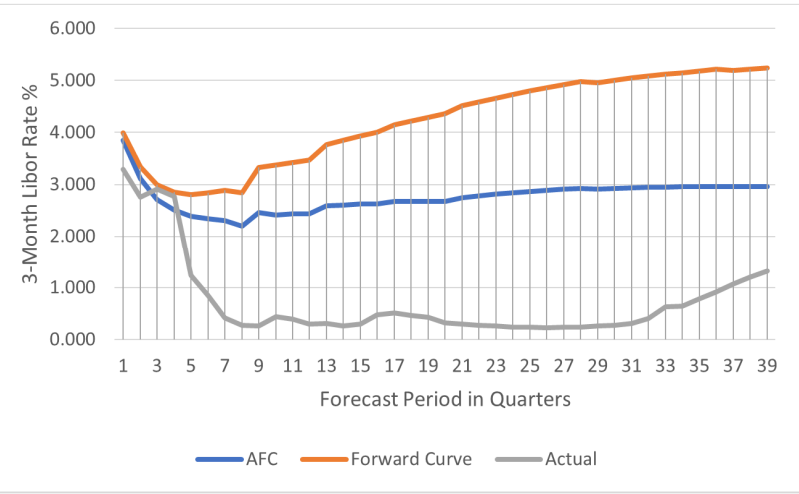

Figure 5. AFC Versus Forward Curve Starting in 2008.

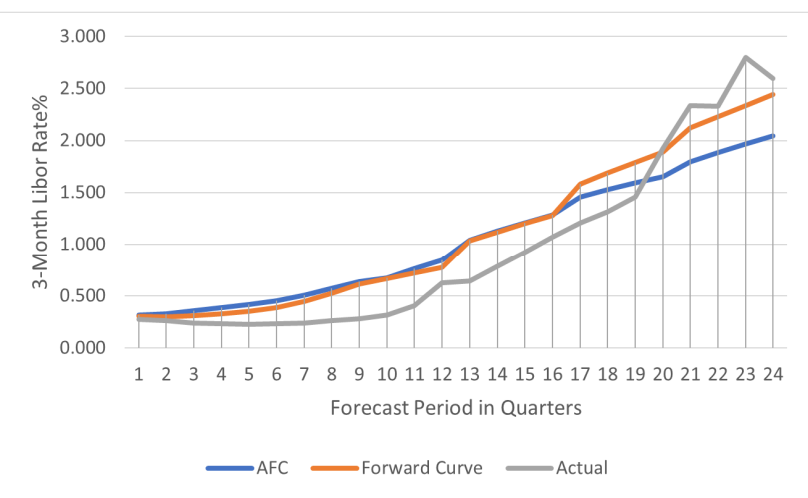

Figure 6. AFC Versus Forward Curve Starting in 2014.

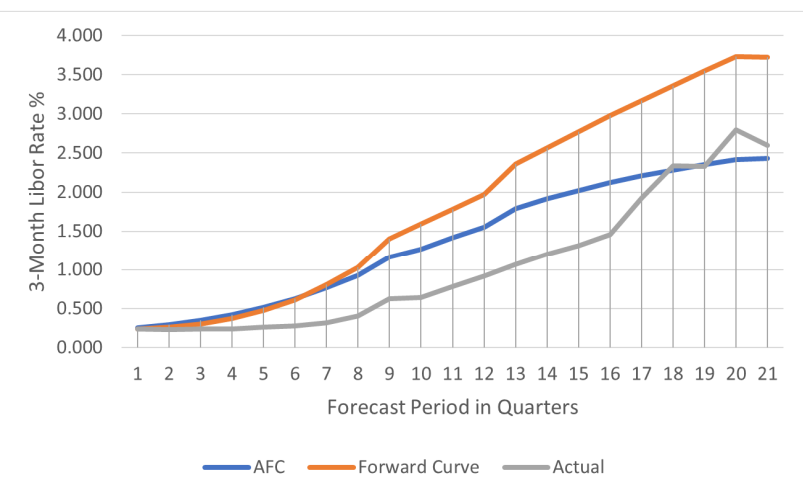

Figure 7. AFC Versus Forward Curve Starting in 2015.

\section{Conclusions}

This paper provided adjustments for liquidity and credit risk to the forward Libor rate in order to improve accuracy of the forward rate in forecasting the 3-month Libor rate.

Consistent with expectations, the AFC the model reveals biases from using the forward rate in projecting the spot rate. The AFC factors that underpin the forward curve bias are statistically relevant with p-values that are less than .00001 . The upward bias in the forward curve (i.e., when the forward curve exceeds the expected future spot rate) positively correlates with the steepness of the yield curve in the AFC model. A downward bias positively correlates with the credit spread and industrial capacity utilization. Furthermore, the effect of the instantaneous forward curve on the future spot rate tempers off with time.

The predictive power of the AFC model, however, hinges on the forecastability of the underlying factors. The testing indicates that all the AFC model factors have a mean reversion component. Therefore, the AFC model should improve long term forecast of the spot rate by adjusting the forward curve with liquidity and credit risk factors that tend to the revert to the mean.

Overall, the AFC model effectively anticipates future movements in the forward curve that tend to yield better forecast of the future spot rate.

\section{References}

[1] Bauer, M. D. and G. D. Rudebusch (2015) "Monetary Policy Expectations at the Zero Lower Bound," Federal Reserve Bank of San Francisco Working Paper Series.

[2] Bernanke, B. S. (1990) "On the Predictive Power of Interest Rates and Interest Rate Spreads," New England Economic Review, 51-68.

[3] Campbell, J. Y., and R. J. Shiller (1991) "Yield Spreads and Interest Rate Movements: A Bird's Eye View." Review of Economic Studies, 58, 495-514.

[4] Clark, T. E., and M. W. McCracken (2012) "Advances in Forecast Evaluation," Handbook of Economic Forecasting, in: G. Elliott \& C. Granger \& A. Timmermann (ed.).

[5] Cochrane, J. H., and M. Piazzesi (2005) "Bond Risk Premia," American Economic Review 95, 138-160. 
[6] Duffee, G. (2013) Forecasting Interest Rates," Handbook of Economic Forecasting, in: G. Elliott \& C. Granger \& A. Timmermann (ed.).

[7] Estrella, A., and G. Hardouvelis (1991) "The Term Structure as a Predictor of Real Economic Activity," Journal of Finance, 46, 555-576.

[8] Fama, E., (1984) "The Information in the Term Structure," Journal of Financial Economics, 13, 509-28.

[9] Fama, E and R. Bliss (1987) "The Information in LongMaturity Forward Rates," American Economic Review, 77, 680-92.

[10] Gibson, R., F. S. Lhabitant,. and D. Talay (2010) "Modeling the Term Structure of Interest Rates: A Review of the Literature, Foundations and Trends" in Finance, 5, p. 1-156.

[11] Gordon, R. J. (1997) 'The Time-Varying NAIRU and its Implications for Economic Policy." The Journal of Economic Perspectives 11, 11-32.

[12] Longstaff, F., and E. Schwartz (1995). "A Simple Approach to Valuing Risky Fixed and Floating Rate Exchange Rate," Journal of Finance, 50, 789-819.
[13] Ludvigson, S. C., and S. Ng, (2009) "Macro Factors in Bond Risk Premia," Review of Financial Studies 22, 5027-5067.

[14] Malkiel, B. G. (2003) "The Efficient Market Hypothesis and Its Critics." Journal of Economic Perspectives, 17, 59-82.

[15] Piazzesi, M., and E. Swanson (2004) "Futures Prices as Risk Adjusted Forecasts of Monetary Policy." NBER Working Paper No. 10547.

[16] Samuelson, P. A. (1965) "Rational Theory of Warrant Pricing," Industrial Management Review, 6, 13-39.

[17] Shiller, R., Campbell, J. Y., and Schoenholtz, K. L. (1983) "Forward Rates and Future Policy: Interpreting the Term Structure of Interest Rates," Brookings Papers on Economic Activity, 173-217.

[18] Stock, J., and M. Watson (1989) "New Indexes of Coincident and Leading Economic Indicators." NBER Macroeconomics Annual 1989, Olivier J. Blanchard and Stanley Fischer, eds., 351-94. Cambridge, Mass.: The M. I. T. Press.

[19] Wu, J. C., and F. D. Xia (2016) "Measuring the Macroeconomic Impact of Monetary Policy at the Zero Lower Bound." Journal of Money, Credit and Banking, 48, 253-291. 